On the Importance of Listening and Intercultural Communication for Actions Against

\title{
Racism
}

\author{
Natalia A. Baires ${ }^{1}$, Rocco Catrone ${ }^{1,2}$, \& Brandon K. May ${ }^{1,3}$ \\ ${ }^{1}$ School of Psychological and Behavioral Sciences, Southern Illinois University \\ ${ }^{2}$ Applied Behavior Analysis Department, The Chicago School of Professional Psychology \\ ${ }^{3}$ Department of Psychiatry, Washington University in St. Louis
}

\begin{abstract}
Author Note
Natalia A. Baires (iD https://orcid.org/0000-0001-6634-4445

Rocco Catrone (iD https://orcid.org/0000-0001-7640-6013

Brandon K. May (iD https://orcid.org/0000-0001-8445-8841

We have no known conflict of interest to disclose.

Correspondence concerning this article should be directed to Natalia A. Baires, Ph.D., BCBA-D, Southern Illinois University. Email: natalia.baires@siu.edu
\end{abstract}




\begin{abstract}
In a period where racial inequities in the United States have garnered more attention and discussion as a result of social media (e.g., increased use of the \#BlackLivesMatter hashtag; Anderson et al., 2020) and newer generations (Tatum, 2017b), it is important to ensure that communication between cultural groups is effective and produces systemic change. This paper will review the failures of a "post-racial" society, with emphasis on ineffective communication between Black, Indigenous People of Color and non-Black, Indigenous People of Color. The role of the listener during intercultural verbal exchanges will be examined, while highlighting the barriers and harmful results of ineffective communication. A behavioral conceptualization of effective listener behavior will be presented, which if implemented, may maintain and sustain social equity, inclusion, and justice. A call to action will be made to further investigate intercultural communication using behavior-analytic research methodologies and how such research might inform on how to functionally and precisely mediate reinforcement in the fight against racism.
\end{abstract}

Keywords: listening, intercultural communication, racism, verbal behavior, diversity 
This manuscript is being published on an expedited basis, as part of a series of emergency publications designed to help practitioners of applied behavior analysis take immediate action to address police brutality and systemic racism. The journal would like to especially thank Denise Ross for their insightful and expeditious reviews of this manuscript. The views and strategies suggested by the articles in this series do not represent the positions of the Association for Behavior Analysis, International or Springer Nature.

Guest Editor, Denisha Gingles 


\section{On the Importance of Listening and Intercultural Communication for Actions Against}

\section{Racism}

Racism is defined as a system that involves prejudice and power, and favors groups based on race (Tatum, 2017a; Wellman, 1993). A behavior analytic account of racist ideologies emphasizes a functional definition of racism and oppression based on language and actions. The present paper will provide an overview of the current state of race relations in the United States (U.S.), define a form of communication between individuals from different cultures, discuss the strengths and barriers to effectively achieving such communication, and propose a method for effective communication between cultural groups, with an in-depth analysis of listener behavior. A potential behavioral model of intercultural listening will be suggested, followed by a call to action for future areas of research regarding this repertoire. In discussing this form of communication from a behavioral perspective, a context can be developed through which racism can be understood based on contingencies of reinforcement utilized by verbal communities and a framework for improving relations between people of different cultures and races can be initiated.

\section{The Utopia of a "Post-Racial" Society}

Racist ideologies and practices date back to the fifteenth century yet remain prevalent within North America today (Wendt, 2009). To some, this may be surprising, partly due to the faulty claims of a "post-racial" society within the U.S., which suggests that issues related to racism are no longer present or relevant (Ono, 2013). Following the election of President Barack Obama, many believed that racial equality had been achieved because the U.S. had elected its first Black/African-American president (Adjei \& Gill, 2011; Burnham, 2008; Curry, 2014; Hier et al., 2009; McKanders, 2010; Teasley \& Ikard, 2010). As proposed by Chen et al. (2015), an 
emerging racial ideology known as "multicultural/multiracial Obama-ism” subsequently began to detail a "post-racial" utopia, as well as new racial policies that focused on the successes of multicultural/multiracial Americans, such as the former president. Specifically, this ideology maintains beliefs of hard work, individual uniqueness, and colorblindness in an effort to minimize, or altogether eliminate, racially systemic inequities.

President Obama's terms in office cannot, however, be considered synonymous with progress towards racial equality (Hochschild et al., 2012). The persistent murders of Black, Indigenous, People of Color (BIPoC) including, but certainly not limited to, Trayvon Martin, Sandra Bland, Breonna Taylor, George Floyd, and Dominique "Rem'mie" Fells either during or after President Obama's terms are evidence that racial equality has yet to be achieved. If ever truly attained, a "post-racial" society would be free from racial bias, discrimination, and prejudice. Activist strategies, such as engaging in protests and advocating for legislation (e.g., protests in Ferguson, Missouri following the police shooting of Michael Brown), have been continuously observed in recent years across the U.S. and college campuses, demonstrating that the fight towards social justice persists, particularly with a new generation (Tatum, 2017b).

The journey that BIPoC have endured in challenging racism, discrimination, and oppression has been far from short and easy, due to what could be considered failed solutions and strategies (Kendi, 2019). Activism, and its many byproducts (e.g., protesting, policy change, etc.), could be argued as a response to the punishing contingencies of control set forth by the majority group (Benson, 2017; Skinner, 1953). Yet despite the continued efforts towards social justice, BIPoC have continuously communicated how the behaviors, practices, and policies of oppressive groups and individuals can change to demonstrate solidarity. For example, protests have called for reform of law enforcement, given the numerous and unjust deaths of BIPoC 
while under custody (President's Task Force on 21st Century Policing, 2015); yet actions at the state and federal levels have been stagnant while BIPoC continue to die. This suggests that nonBIPoC are only hearing BIPoC and not listening to them. Considering that a truly "post-racial" society has yet to be achieved, the role of non-BIPoC as listeners and how they can engage in effective intercultural communication necessitates attention.

\section{The Role of the Listener}

Skinner (1957) defined the role of the listener as mediating reinforcement of the speaker. As a verbal community shapes the verbal behavior of a speaker, it also shapes the form and function of the listener's behavior for mediating contingencies. The role of the listener has significant implications on the behavior of the speaker and needs to be accounted for in order to have a comprehensive analysis of a speaker-listener interaction (Parrot, 1984). According to Skinner (1957), it means very little to say that a listener "understands" a speaker until the listener engages in some form of overt behavior that mediates reinforcement for the speaker's behavior. In the context of racism, a listener may "know about" or "understand" systemic racism but not mediate precise reinforcement for the speaker's behavior by engaging in behavior that counters the ongoing cultural contingencies of oppression.

The present paper takes a functional perspective to communication between members of different groups. According to Skinner (1957), words may have similar topographies but serve different functions. For example, under one set of environmental contingencies, the word "justice" may be emitted to tact or label an action of justice, but may be emitted under different environmental contingencies due to deprivation of justice (i.e., mand). Intercultural Communication (ICC) will be reviewed by synthesizing research outside of behavior analysis under the behavior analytic lens followed by identifying various barriers and effects on 
ineffective ICC. In an effort to specify the behaviors of these repertoires, the following sections will clarify actionable steps in order for listeners to mediate more precise reinforcement for BIPoC's verbal behavior within the context of racism. Each of these steps consider the overt and covert verbal behaviors associated with the role of the listener, as well as the interaction between form and function. Future lines of research will conclude the paper in order for practitioners and academics alike to address this important and emerging area of study for the betterment of the field.

\section{Intercultural Communication}

According to the U.S. Census Bureau (2020), China, the U.S., Pakistan, Brazil, and Russia are among the top 10 most populous countries. Over $25 \%$ of the U.S. population is composed of first- or second-generation immigrants (U.S. Census Bureau, 2020). These data speak to the variety of races, ethnicities, cultures, and languages around the world and within the U.S. When discussing the role of communication between parties, the involvement of different cultural groups warrants consideration. As defined by Abu-Arqoub and Alserhan (2019), ICC is exemplified when two or more parties with different cultural backgrounds communicate with one another. Here, the ultimate value of ICC is to effectively communicate ideas, wants, and needs between individuals from different cultures.

From a Skinnerian perspective (Skinner, 1957, 1981), effective ICC can be defined as a speaker from one cultural group and a listener from another cultural group engaging in a verbal exchange, where the listener mediates reinforcement for the verbal behavior emitted by the speaker. In other words, speakers and listeners with different learning histories, as formulated by their respective verbal communities, are observed to respond to each other's discriminative stimuli during a verbal exchange. This may be exemplified by a BIPoC asking a non-BIPoC a 
question (i.e., intraverbal), to which the non-BIPoC provides a response (i.e., generalized conditioned reinforcement).

Within ICC, the learning histories and cultural backgrounds of a speaker and listener can have an impact on the verbal behavior (whether vocal or not) emitted during a verbal exchange. As defined by Glenn (2004), culture can be considered as a set of products (e.g., technologies, organizations, etc.) and learned behaviors that are socially transmitted by a group of people. Therefore, it is likely that members from the same culture will mediate reinforcement for each other's verbal and non-verbal behavior more accurately (Hulbert, 1994). However, when a speaker and listener come from different cultural groups, the probability of erroneously mediating reinforcement for verbal and non-verbal behavior likely increases due to the unfamiliarity of behaviors and contingencies, thus creating barriers towards effective ICC. These barriers can impact any future occurrences of verbal exchanges, as well as diminish future opportunities for the speaker to contact reinforcement as mediated by the listener.

\section{Barriers Toward Effective Intercultural Communication}

Within behavior analysis, the ultimate goal of communication should be that the behavior of both parties mediates and contacts the corresponding type of reinforcement within verbal exchanges (e.g., the stimulus specified as a result of a mand). As previously mentioned, this can be difficult when there are two different learning histories which, in and of itself, can create barriers before verbal exchanges commence. There are several barriers to ensure effective ICC, including, but not limited to, a) non-verbal barriers (Abu-Arqoub \& Alserhan, 2019), b) language differences (Baltador \& Budac, 2014), c) ethnocentrism, and d) stereotypes, prejudice, and discrimination (Maljichi, 2019). 
Non-vocal barriers. To most, the term "non-verbal" refers to the physical cues a speaker emits when communicating or the physical cues emitted in absence of a vocalization (Dyers \& Wankah, 2010). However, since behavior analysts define communication functionally, some behavior may be verbal but not vocal (e.g., audible; Skinner, 1957). To discriminate between the two, behavior that does not include audible sound will be defined as non-vocal. All cultures have some form of non-vocal behavior (Wang \& Li, 2007), which provide context for conversations. For example, in the U.S., nodding one's head indicates agreement and shaking one's head indicates disagreement, while the opposite is seen in India (Abu-Arqoub \& Alserhan, 2019). If a speaker from India were to describe their experiences with discrimination to a listener from the U.S. who then began to nod their head in agreement, a barrier to effective ICC would likely emerge because of the differences in learning histories with the behavior of nodding one's head. Overall, being unfamiliar with a speaker's verbal learning history and how to mediate different or inaccurate consequences can potentially generate non-vocal cultural barriers during ICC.

Language differences. Language differences are perhaps the most evident barrier towards effective ICC. If the speaker and listener have a verbal exchange in a language in which neither are highly proficient, only one party is familiar with, or if the same language is spoken by parties who are from different cultures, effective communication can be impacted. Moreover, discrepancies with grammar, linguistic style, semantics (i.e., an individual's life experiences), and phonetics (i.e., how things sound) may occur (Akhmetshin et al., 2017).

Cognates are one example of a language difference that may impact effective ICC. Defined as translated words that share phonology, such as "racism" in English, "racismo" in Spanish, and "razzismo" in Italian, cognates may offer some cross-cultural/language understanding. However, it is important to note that cognates occur within the context of a 
sentence in a spoken language, where differences in grammar and sentence structure can alter the meaning of the sentence. While cognates can assist parties engaging in ICC, limitations may arise when utilizing them outside of the cultural context. According to Proctor and Mo (2009), much of a language's direct translations, including cognates, are not contextually defined in the same manner and are highly dependent on sentence structures. As a result, direct translations may fail to communicate the intended meaning, which likely leads to misunderstandings between communicative partners. To acquire the full meaning of a cognate, a listener would have to understand and be able to accurately use (or be fluent in) the language or dialect (Proctor \& Mo, 2009).

Ethnocentrism. Defined as the belief that customs and practices from one's culture are superior to the cultures of others, ethnocentrism maintains the notion that one's culture teaches the "right" and "wrong" ways to behave and that those who behave differently are "wrong" (Maljichi, 2019). From a behavior analytic perspective, cultures mediate reinforcement for particular practices across generations. However, failing to acknowledge that other cultures have different practices may create barriers to communication. Ethnocentrism can be extended to include verbal behavior, where discussing or not discussing particular topics can be considered "right" or "wrong" in one culture, while is it the opposite within another culture. For instance, some cultures may punish conversations about race or racism, while others mediate reinforcement for such conversations. The literature has continuously recommended that conversations about and the acknowledgement of racial differences and racial biases, as opposed to the omission of such activities, are needed in order to move towards social equity and justice (e.g., Biafora et al., 1993; Chesler et al., 2003; Gooden \& O’Dorherty, 2015; Jones, 2020; Katz, 1981; Sleeter, 1992). Therefore, groups that mediate punishment for conversation topics centered 
around racism can not only contribute to barriers encountered within effective ICC, but may even decrease instances or opportunities for verbal exchanges with groups that mediate reinforcement for such topics.

Stereotypes, prejudice, and discrimination. Finally, the role of stereotypes, prejudices, and discriminations also impact effective ICC, especially if the two parties involved in a verbal exchange are from different cultures or groups (Baltador \& Budac, 2014). Although stereotypes can be positive or negative, they can be easily established and difficult to remove (Maljichi, 2019; Matsuda et al., 2020). From a behavior analytic perspective, racial stereotypes, prejudices, and biases can be acquired without direct exposure to contingencies of reinforcement as a result of responding to one stimulus in relation to another stimulus. For instance, an accent from a speaker may be paired with a listener's prejudiced learning history (Gluszek \& Dovidio, 2010). If through verbally-mediated learning histories, "accent" for the listener is associated with "lower intelligence" or an inability to articulate in a coherent way, this verbal exchange may be influenced. Prejudice or stereotypes may also be strengthened when a speaker and listener speak in different languages (Akhmetshin et al., 2017; Logan et al., 2014; Mancini-Cross et al., 2009). Whereas stereotypes and prejudices refer to covert behaviors, discrimination commonly refers to overt behaviors. According to Maljichi (2019), biases and forms of discrimination are often observed because of one's preference for, and loyalty to, one's personal culture. Forms of discrimination can be observed subtly or non-vocally (e.g., avoiding eye contact), vocally (e.g., directing insults at someone), physically (e.g., engaging in physical aggression), or systemically (e.g., not hiring someone due to their age). These prejudices and forms of discrimination may impact teaching members of a community how to engage in effective ICC (Spencer-Rogers \& McGovern, 2002) and subsequently transmit across future generations of that verbal community. 


\section{Physiological Impacts}

Given the aforementioned barriers that impact effective ICC, it is crucial to discuss any adverse effects or stressors that can emerge. Research has found differences in cardiovascular activity within white individuals when interacting with individuals who they hold stigmas towards and perceive as threatening compared to individuals they do not hold stigmas towards and do not perceive as threatening (Blascovich et al., 2001; Foster, 2018). For Black/AfricanAmerican individuals, Clark et al. (1999) provided an extensive review that provides evidence for increased psychological and physiological stress responses following perceptions of racism with peers. Although BIPoC and non-BIPoC may experience the aforementioned adverse effects following conversations about racism with one another, a psychological toll, among other things, can specifically be brought on for $\mathrm{BIPoC}$ when they are expected to be the sole/primary source of learning for their white peers (Richeson \& Shelton, 2007) and when their repeated advocacy for social equity, inclusion, and justice are incessantly ignored. From a behavior analytic perspective, this suggests that the role of listeners may not be fully functional, in that equity, inclusion, and justice (i.e., reinforcement) is being topographically, but not functionallymediated (e.g., does the release of a statement of diversity truly lead to the decrease of racist practices within an organization?).

\section{Effective Intercultural Communication Repertoires}

Given the aforementioned barriers and their potentially harmful effects, the repertoires of effective listening should be the target of one's own behavior change. As previously discussed, this may pose difficulties in effective ICC. Although Abu-Arqoub and Alserhan (2019) provide a definition for ICC, the specification of behaviors (both overt and covert) that would allow for effective ICC are not mentioned. The following sections provide overarching considerations for 
effective ICC based on potential barriers as identified by empirical research and behavioral conceptualizations of Headlee (2017)'s suggestions on effective communication.

\section{Patience during Language Discrepancies}

One consideration regarding language differences between communicative partners relates to the listener using direct language and simplified speech when uncertain about what the speaker has said. Logan et al. (2014) calls for the listener to be engaged with the speaker's verbal behavior, even if it may differ from what the listener has been taught as important in their own culture, such as in instances where the speaker and listener do not share the same primary language. As a listener who is fluent in the language that the speaker is using but the speaker is not fluent in, translating between these languages may not convey the meaning the speaker had intended. A phrase or idiom may have a verbally mediated meaning in one culture as being "funny" yet when transferring to another culture, may offend the listener (and vice versa).

Logan et al. (2014) further suggest that in these situations, direct language (e.g., without alternate meaning or metaphors) and simplified speech (i.e., using short sentences, repeating words, using smaller alternate words, etc.) be used. Although the listener becomes the speaker in this instance, this may be a necessary step to further mediating proper reinforcement for the speaker's behavior during ICC. Thus, attending to the overall meaning of the conversation and asking clarifying questions to ensure understanding is paramount so as to not promote confusion and tension, and to more importantly mediate precise reinforcement on behalf of the listener. However, asking clarifying questions also has the potential to offend, as in cases of a non-BIPoC asking a BIPoC where they were born, where their family is from, and where they are actually from. Therefore, listeners need to remain thoughtful about trying to avoid asking questions that 
are common microaggressions experienced by $\mathrm{BIPoC}$ in asking questions to prevent unintentionally offending the speaker.

\section{Caution Regarding Multitasking}

Next, Headlee (2017) recommends that effective listeners refrain from attending to any unnecessary details during verbal exchanges. When extraneous verbal stimuli are included within a verbal exchange (e.g., names, dates, details of things, etc.), the focus of the topic can be lost, which may impact opportunities for listeners to mediate precise reinforcement for speakers. This interaction with a variety of overt verbal stimuli, while simultaneously interacting with covert verbal behavior, can be defined as multitasking. From the behavioral perspective, the listener only engages with the discriminative stimuli $\left(\mathrm{S}^{\mathrm{D}}\right)$ that the speaker is emitting and as little as possible with their own private $\mathrm{S}^{\mathrm{D}} \mathrm{s}$ or covert behavior.

Headlee (2017) states that if one is focused on how to respond to something the speaker is saying, the listener is not fully attending to what the speaker is saying, which may lead to misinterpretations of what is being said. Although a practical and theoretical guide focused on clinical contexts, the book Mindfulness for Two (Wilson \& DuFrene, 2009) offers the suggestion to stay with the client (i.e., speaker) and not engage in one's own private events during a verbal exchange. Therefore, a potential solution for noticing private events (i.e., covert $\mathrm{S}^{\mathrm{D}} \mathrm{s}$ ) but not responding to them would entail letting those private events pass while staying engaged in the present moment with the speaker. It is imperative to keep multitasking to a minimum, as derived relations occur without the organism's active awareness (Dymond et al., 2018); therefore, to actively engage with these derived relations is to distract from the speaker's verbal stimuli.

\section{Limiting Listener Interjection}


Another important area that can help strengthen the repertoire of an effective listener is to actively listen and not interrupt the speaker. According to Headlee (2017), this includes refraining from equating one's personal experiences to those of the speaker's. Specifically, to this skill that listeners can enhance, it may be the case that the verbal community does not train listeners to effectively mediate reinforcement for speakers who discuss any aversive or painful experiences, such as the loss of a family member. During those verbal exchanges, listeners may try to comfort the speaker, empathize with them, and let them know they understand what is being experienced by discussing a similar experience from the past (Headlee, 2017). Instead of truly empathizing with the speaker, equating one's experiences with that of the speakers' moves the anguish and attention from the speaker to the listener, which does not likely mediate the type of reinforcement a speaker wishes to contact. As listeners, it is important to remember that even though we may have experienced something similar to what the speaker is describing, the two experiences will never be the same, especially when accounting for contextual variables and learning histories.

\section{Welcoming Difficult Conversations}

To mediate precise reinforcement for speakers in the fight against racism, listeners are strongly encouraged to have conversations with individuals who have opposing views. With this specific recommendation, Headlee (2017) elaborates within the context of racism. Headlee (2017) states that although there may be disagreements between a speaker and listener, the opportunity to have a verbal exchange or respect one another should not be compromised. Moreover, disagreeing on one issue, albeit very important, does not indicate that disagreements will be had across other issues. Specific to racism, for listeners who are working towards antiracism, it may be tempting to avoid having conversations with speakers who express racist or 
racially biased views. In considering that everyone holds implicit biases, whether negative or positive (Hahn \& Gawronski, 2019), effective listeners should remain aware of the presence of these private events and that not acknowledging bias or labeling others who overtly demonstrate their biases is limiting in mediating reinforcement for BIPoC in relation to racism.

Moreover, members of different verbal communities are encouraged to have conversations about racism, even though they are likely to be uncomfortable. Naturally, speakers and listeners are likely to avoid unpleasant or aversive stimuli. However, progress towards social equity, inclusion, and justice will continue to be limited if uncomfortable topics related to race or racial biases are punished or avoided. Yet for BIPoC, there may be learning histories of punishment and/or extinction in relation to having conversations about racism; this speaks to the continual importance of listeners mediating reinforcement for BIPoC speakers. Opportunities for listeners to actively listen and learn about BIPoC's experiences will also be restricted, which in turn, inhibit instances in which listeners can effectively mediate reinforcement to counter racist behaviors and practices.

\section{Concluding Considerations}

Given the persistent and systemic issues repeatedly experienced by BIPoC in the U.S., behavior analysts must recognize and actively address these inequities. Within all contexts, we must be effective listeners and precisely mediate the much needed and specified reinforcement that $\mathrm{BIPoC}$ have been clearly stating for centuries. However, systemic racism is the coalescence of complex learning histories shaped by verbal communities, which may be addressed in separate units (e.g., behavioral repertoires of groups). As with any effective behavioral program designed for cultural change, smaller steps may be taken to shape appropriate behavioral repertoires. As such, the intention of this paper was to briefly review the topic of ICC, provide an overview for 
how behavior analysts may explain ICC, and offer suggestions for how more effective listening skills might be incorporated into verbal exchanges in the fight against racism. To truly evaluate the premises outlined above, well designed research protocols must be developed. Thus, the next section will describe some possible areas of research that would benefit behavior analysis and society at large.

\section{Potential Future Research}

One potential area of future research would be to create a more behaviorally oriented model of ICC in order to objectively observe and measure behaviors that promote effective ICC. Although the analytic framework in the present paper was Skinnerian, an analysis from a Relational Frame Theory approach (Hayes et al., 2001) would be additive. This may be done through the analysis of whether relational frames differ in the frequency of use, meaning, and context across cultures. Moreover, this may extend to analyzing interactions that take place within clinical settings between BIPoC clients and other BIPoC practitioners or non-BIPoC practitioners.

Another potential area for future research could include a contextual analysis of gestures and other non-vocal behavior in relation to ICC. Given that gestures differ across cultures (Houssos, 2020; Wang \& Li, 2007; Zand et al., 2020), and can even be dependent in creating meaning for high context cultures (e.g., cultures where the context of communication relies heavily on non-vocal gestures; Dyers \& Wankah, 2010), a behavioral analysis and evaluation of the topographical and functional relationships is needed.

Evaluating the effects of effective ICC on treatment fidelity and social validity would be another area for fruitful research. Considering that the majority of Board Certified Behavior Analysts at the masters and doctoral levels self-identify as white females ( $86 \%$; Beaulieu et al., 
2019; Behavior Analyst Certification Board, n.d.; Nosik et al., 2019), it is important to assess ICC, particularly with families who self-identify as BIPoC. This area of research can be especially important for identifying relations between demographic variables and behavioranalytic procedures. For instance, Jones et al. (2020) found that among articles published in the Journal of Applied Behavior Analysis between 2013-2019, race or ethnicity, language, and socioeconomic status were the least reported demographics variables $(7 \%, 4 \%$, and $2 \%$ respectively). These data may suggest the lack of effective ICC in considering clients' culture during the provision of behavior-analytic services, which may impact treatment fidelity and social validity.

\section{Final Remarks}

According to Benson (2017), effective communication can be utilized in the service of grassroots activism and advocacy. Although all behavior can be considered functional, occasionally the impact of the behavior on others may be harmful. Even when speakers and listeners engage in verbal exchanges, barriers towards effective communication can be encountered, particularly if both parties have different racial, ethnic, or cultural backgrounds. With acts and practices of racial oppression being more apparent and discussed than ever, it is important to analyze the skills of an effective listener in order to functionally target communication between cultures. The role of listening within an intercultural context should be to actively engage with the verbal stimuli of speakers in order to identify and mediate precise reinforcement of such verbal behavior. As a science that utilizes a functional approach to studying behavior, behavior analysts need to continually evaluate whether the mediation of reinforcement is truly functional for BIPoC in dismantling racism or not. Our time in not adequately targeting racism is up. Serving as precise listeners can not only diminish the harmful 
and discriminatory practice of racism, but it may ultimately contribute to ending violence against BIPoC. 


\section{Compliance with Ethical Standards}

Ethical approval: This article does not contain any studies with human participants or animals performed by any of the authors.

Informed Consent: N/A

Conflict of Interest: The authors declare that they have no conflict of interest. 


\section{References}

Abu-Arqoub, I. A. \& Alserhan, F. A. (2019). Non-verbal barriers to effective intercultural communication. Utopía y Praxis Latinoamericana, 24(5), 307-316.

Adjei, P. B., \& Gill, J. K. (2012). What has Barack Obama's election victory got to do with race? A closer look at post-racial rhetoric and its implication for antiracism education. Race, Ethnicity, and Education, 16(1), 134-153. http://dx.doi.org/10.1080/13613324.2011.645576

Akhmetshin, E. M., Makulov, S. I., Talysheva, I. A., Fedorova, S. Y., \& Gubarkov, S. (2017). Overcoming of intercultural barriers in the educational environment. Man in India, $97(15), 281-288$.

Anderson, A., Barthel, M., Perrin, A., \& Vogels, E. A. (2020, June 10). \#BlackLivesMatter surges on Twitter after George Floyd's death. Pew Research Center. https://www.pewresearch.org/fact-tank/2020/06/10/blacklivesmatter-surges-on-twitterafter-george-floyds-death/

Baltador, L., \& Budac, C. (2014). Intercultural communication barriers: An interpersonal approach. Revista Economică, 66(1), 28-36.

Behavior Analyst Certification Board. (n.d). BACB certificant data. https://www.bacb.com/BACB-certificant-data

Beaulieu, L., Addington, J., \& Almeida, D. (2019). Behavior analysts' training and practices regarding cultural diversity: The case for culturally competent care. Behavior Analysis in Practice, 12(3), 557-575. https://doi.org/10.1007/s40617-018-00313-6

Benson, M. (2017). Advocating for activism. Behavior and Social Issues, 26, 187-189. https://doi.org/10.5210/bsi.v26i0.8240 
Biafora Jr, F. A., Taylor, D. L., Warheit, G. J., Zimmerman, R. S., \& Vega, W. A. (1993).

Cultural mistrust and racial awareness among ethnically diverse Black adolescent boys. Journal of Black Psychology, 19(3), 266-281.

https://doi.org/10.1177/00957984930193003

Blascovich, J., Mendes, W. B., Hunter, S. B., Lickel, B., \& Kowai-Bell, N. (2001). Perceiver threat in social interactions with stigmatized others. Journal of Personality and Social Psychology, 80(2), 253-267. https://doi.org/10.1037/0022-3514.80.2.253

Burnham, L. (2008). Obama's candidacy: The advent of post-racial American and the end of Black politics? The Black Scholar, 38(4), 43-46. https://doi.org/10.2307/41069365

Chen, Y., Simmons, N., \& Kang, D. (2015). “My family isn’t racist--however ...”: Multiracial/Multicultural Obama-ism as an ideological barrier to teaching intercultural communication. Journal of International and Intercultural Communication, 8(2), 167186. https://doi.org/10.1080/17513057.2015.1025331

Chesler, M. A., Peet, M., \& Sevig, T. (2003). Blinded by whiteness: The development of white college students' racial awareness. In E. Bonilla-Silva \& E. Doane (Eds.), White out: The continuing significance of racism (pp. 215-230). Routledge.

Clark, R., Anderson, N. B., Clark, V. R., \& Williams, D. R. (1999). Racism as a stressor for African Americans: A biopsychosocial model. American Psychologist, 54(10), 805-816. https://doi.org/10.1037/0003-066X.54.10.805

Curry, T. J. (2014). Back to the woodshop: Black education, imperial pedagogy, and post-racial mythology under the reign of Obama. Teachers College Record, 117(14), 27-52. 
Dyers, C. \& Wankah, F. J. (2010). Uncovering and negotiating barriers to intercultural communication at Greenmarket Square, Cape Town's "World in miniature": An insider's perspective. Per Linguam, 26(1), 1-12. https://doi.org/10.5785/26-1-10

Dymond, S., Bennett, M., Boyle, S., Roche, B., \& Schlund, M. (2018). Related to anxiety: Arbitrarily applicable relational responding and experimental psychopathology research on fear and avoidance. Perspectives on Behavior Science, 41(1), 189-213. https://doi.org/10.1007/s40614-017-0133-6

Foster, C.S. (2018). (Don't) Stand by Me: Social Regulation of Response to Threat in Interracial Dyads. Dissertations. 3320. Retrieved from: https://scholarworks.wmich.edu/dissertations/3320

Glenn, S. S. (2004). Individual behavior, culture, and social change. The Behavior Analyst, 27(2), 133-151. https://doi.org/10.1007/BF03393175

Gluszek, A., \& Dovidio, J. F. (2010). The way they speak: A social psychological perspective on the stigma of nonnative accents in communication. Personality and social psychology review, 14(2), 214-237. https://doi.org/10.1177/1088868309359288

Gooden, M. A., \& O’Doherty, A. (2015). Do you see what I see? Fostering aspiring leaders' racial awareness. Urban Education, 50(2), 225-255. https://doi.org/10.1177/0042085914534273

Hahn, A., \& Gawronski, B. (2019). Facing one's implicit biases: From awareness to acknowledgment. Journal of Personality and Social Psychology, 116(5), 769-794. https://doi.org/10.1037/pspi0000155 
Hayes, S. C., Barnes-Holmes, D., \& Roche, B. (Eds.). (2001). Relational frame theory: A postSkinnerian account of human language and cognition. Kluwer Academic/Plenum Publishers.

Headlee, C. (2017). We need to talk: How to have conversations that matter. Hachette.

Hier, S. P., Lett, D., \& Bolaria, B. S. (2009). Racism and justice. Critical dialogue on the politics of identity, inequality, and change. Fernwood Publishing.

Hochschild, J., Weaver, V., \& Burch, T. (2012). Creating a new racial order: How immigration, multiracialism, genomics, and the young can remake race in America. Princeton University Press.

Houssos, V. (2020). Culture-specific nonverbal communication and the teaching of foreign language. Multilingual Academic Journal of Education and Social Sciences, 8(1) 90-102. https://dx.doi.org/10.46886/MAJESS/v8-i1/6968

Hulbert, J. E. (1994). Overcoming intercultural communication barriers. Bulletin of the Association for Business Communication, 57(1), 41-44.

Jones, L. (2020). Pain, anger and youth resistance: Police racial awareness training and the contemplations of a black mother. In J. Etienne (Ed.), Communities of Activism: Black women, higher education and the politics of representation (pp. 91-109). Trentham Books

Jones, S. H., St. Peter, C. C., \& Ruckle, M. M. (2020). Reporting of demographic variables in the Journal of Applied Behavior Analysis. Journal of Applied Behavior Analysis, 53(3), 1304-1315. https://doi.org/10.1002/jaba.722

Katz, P. A. (1981). Development of children's racial awareness and intergroup attitudes. National Institute of Education. 
Kendi, I. X. (2019). Failure. In I. X. Kendi (Ed.), How to be an antiracist (pp. 201-216). Penguin Random House

Logan, S., Steel, Z., \& Hunt, C. (2014). A systematic review of effective intercultural communication in mental health. Cross-Cultural Communication, 10(5), 1-11. http://dx.doi.org/10.3968/5407

Maljichi, D. (2019). Barriers of intercultural communication. Vizione, 32, 81-89.

Mancini-Cross, C., Backman, K. F., \& Baldwin, E. D. (2009). The effect of the language barrier on intercultural communication: A case study of educational travel in Italy. Journal of Teaching in Travel \& Tourism, 9(1-2), 104-123. https://doi.org/10.1080/15313220903042004

Matsuda, K., Garcia, Y., Catagnus, R., \& Brandt, J. A. (2020). Can behavior analysis help us understand and reduce racism? A review of the current literature. Behavior Analysis in Practice, 13(1), 336-347. https://doi.org/10.1007/s40617-020-00411-4

McKanders, K. M. (2010). Black and Brown coalition building during the "post-racial" Obama era. St. Louis University Public Law Review, 30(1), 473-499. https://dx.doi.org/10.2139/ssrn.1670921 Parrot, L. J. (1984). Listening and understanding. The Behavior Analyst, 7(1), 29-39. https://doi.org/10.1007/BF03391883

Nosik, M. R., Luke, M. M., \& Carr, J. E. (2019). Representation of women in behavior analysis: An empirical analysis. Behavior Analysis: Research and Practice, 19(2), 213-221. http://dx.doi.org/10.1037/bar0000118 
Ono, K. A. (2013). Mad men's postracial figuration of a racial past. In M. E. L. Goodlad, L. Kaqanovsky, \& A. R. Rushing (Eds.), Madmen, madworld: Sex, politics, style and the 1960s (pp. 300-319). Duke University Press.

President's Task Force on 21st Century Policing. (2015). Final report. Washington, DC: Office of Community Oriented Policing Services.

Proctor, C. P., \& Mo, E. (2009). The relationship between cognate awareness and English comprehension among Spanish-English bilingual fourth grade students. TESOL Quarterly, 43(1), 126-136. https://doi.org/10.1002/j.1545-7249.2009.tb00232.x

Richeson, J. A., \& Shelton, J. N. (2007). Negotiating interracial interactions: Costs, consequences, and possibilities, Current Directions in Psychological Science. 16(6), 316320. https://doi.org/10.1111/j.1467-8721.2007.00528.x

Skinner, B. F. (1953). Personal control. In B. F. Skinner (Ed.), Science and Human Behavior (pp. 313-322). Free Press.

Skinner, B. F. (1957). Verbal behavior. Copley Publishing Group.

Skinner, B. F. (1981). Selection by consequences. Science, 213(4507), 501-504. https://doi.org/10.1126/science.7244649

Sleeter, C. E. (1992). Resisting racial awareness: How teachers understand the social order from their racial, gender, and social class locations. The Journal of Educational Foundations, $6(2), 7-32$.

Spencer-Rodgers, J., \& McGovern, T. (2002). Attitudes toward the culturally different: The role of intercultural communication barriers, affective responses, consensual stereotypes, and perceived threat. International Journal of Intercultural Relations, 26(6), 609-631. https://doi.org/10.1016/S0147-1767(02)00038-X 
Tatum, B. D. (2017a). Defining racism: “Can we talk?” In B. D. Tatum (Ed.), Why are all the Black kids sitting together in the cafeteria? And other conversations about race (2nd ed., pp. 83-97). Basic Books.

Tatum, B. D. (2017b). Prologue. In B. D. Tatum (Ed.), Why are all the Black kids sitting together in the cafeteria? And other conversations about race (2nd ed., pp. 1-72). Basic Books.

Teasley, M., \& Ikard, D. (2010). Barack Obama and the politics of race. The myth of postracism in America. Journal of Black Studies, 40(3), 411-425. https://doi.org/10.1177/0021934709352991

United States Census Bureau (2020, July). U.S. and world population clock. https://www.census.gov/popclock/world

Wang, D. H., \& Li, H. (2007). Nonverbal language in cross-cultural communication. Sino-US English Teaching, 4(10), 66-70.

Wellman, D. T. (1993). Prejudiced people are not the only racists in America. In D. T. Wellman (Ed.), Portraits of White racism (2nd ed., pp. 27-62). Cambridge University Press. https://doi.org/10.1017/CBO9780511625480

Wendt, S. (2009). Transnational perspectives on the history of racism in North America. Amerikastudien, 54(3), 473-498. https://doi.org/10.2307/41158451

Wilson, K. G. \& DuFrene T. (2009). Mindfulness for two: An Acceptance and Commitment Therapy approach to mindfulness in psychotherapy. New Harbinger Publications.

Zand, S., Baradaran, M., Najafi, R., Maleki, A., \& Golbazi Mahdipour, A. (2020). Culture and Gender in nonverbal communication. Rooyesh-e-Ravanshenasi, 8(12), 123-130. 